Check for updates

Cite this: RSC Adv., 2018, 8, 3958

\title{
Orthorhombic $\mathrm{SnO}_{2}$ phase observed composite $\left(\mathrm{Sn}_{1-x} \mathrm{Ce}_{x}\right) \mathrm{O}_{2}$ synthesized by sol-gel route $\uparrow$
}

\begin{abstract}
M. H. Carvalho, (D) *a E. C. Pereira ${ }^{\text {b }}$ and A. J. A. de Oliveira (D)*a
Semiconductor oxides are a class of materials used in many different applications, such as catalysis, solar cells and magnetic devices. In particular, composites with different semiconducting oxides follow synergetic effects with changes of electrical conductivity or magnetic properties. In this case, the synthesis conditions are very important for controlling their properties due to structural defects and non-stable phases at room temperature. In this paper, we analyzed the influence of the synthesis temperature and different concentrations of cerium in the formation of the orthorhombic $\mathrm{SnO}_{2}$ phase. The structural and morphological characterization was performed using experimental techniques such as $X$-ray diffraction (XRD), allied with Rietveld refinement, field emission scanning electron microscopy (FESEM), transmission electron microscopy (TEM) and energy dispersive $X$-ray spectroscopy (EDS). The reflections in the XRD pattern and clear lattice fringes observed by HRTEM confirm the formation of the orthorhombic $\mathrm{SnO}_{2}$ phase in the $\left(\mathrm{Sn}_{1-x} \mathrm{Ce}_{x}\right) \mathrm{O}_{2}$ with $x=0,0.05,0.1$ and 0.3 synthesized at $750{ }^{\circ} \mathrm{C}$. The reducing atmosphere generated by the heat treatment process of the samples and the strain originated due to the difference of ionic radii between the tin and cerium ion can play a crucial role in the formation of the orthorhombic phase of $\mathrm{SnO}_{2}$.
\end{abstract}

Received 23rd November 2017

Accepted 5th January 2018

DOI: $10.1039 / c 7 r a 12727 h$

rsc.li/rsc-advances
The formation of the orthorhombic phase is directly related to the synthesis method used, as well as to other experimental conditions, such as pressure, and temperature. Although originally this phase was found only in experiments carried out at high pressure and temperature, new synthesis strategies have been proposed to prepare $\mathrm{O}-\mathrm{SnO}_{2}$ under atmospheric pressure. In this sense, different physical and chemical routes, such as pulsed laser deposition (PLD) $)^{\mathbf{8}, 9}$ oxidizing epitaxial tin monoxide films, ${ }^{10}$ metalorganic chemical vapor deposition (MOCVD) $^{\mathbf{1 1}}$ and co-precipitation methods ${ }^{\mathbf{1 2}}$ were used to synthesize this phase. For example, Chen et al. prepared pure O$\mathrm{SnO}_{2}$ thin films at a pressure of $3 \times 10^{-2} \mathrm{~Pa}$ and substrate temperature of $320{ }^{\circ} \mathrm{C}$ using pulsed laser deposition (PLD). ${ }^{8}$ Lamelas et al. investigated the formation of nanoparticles with orthorhombic phase produced by the oxidation of mechanically milled tin monoxide powders, followed by a heating to $575^{\circ} \mathrm{C}^{13}$ Using a different approach, Zhang et al., proposed to dope the $\mathrm{SnO}_{2}$ with $\mathrm{Mn}$ to obtain the orthorhombic phase. The authors reported a mixture of $\mathrm{O}-\mathrm{SnO}_{2}$ and $\mathrm{T}-\mathrm{SnO}_{2}$ for samples processed at ambient pressure doped with $5 \mathrm{~mol} \%$ of $\mathrm{Mn} .{ }^{12}$ Using a similar strategy, we investigated the doping process of $\mathrm{SnO}_{2}$ with a rare earth metal (RT). Among the RT, we chose cerium doping, since it has two oxidation states and ionic radius with the coordination number equal to $6, \mathrm{Ce}^{3+}(1.01 \AA)$ and $\mathrm{Ce}^{4+}(0.87 \AA)$, respectively, much larger than the $\mathrm{Sn}^{4+}(0.69 \AA)$, with the same coordinate number. ${ }^{14}$ This could induce stress in the $\mathrm{SnO}_{2}$ lattice, possibly leading to the formation of the orthorhombic phase.
${ }^{a}$ Physics Department, Federal University of São Carlos, UFSCar, P. O. Box 676, 13565-905, São Carlos, SP, Brazil.E-mail: adilson@df.ufscar.br; helenacarvalho@ df.ufscar.br

${ }^{b}$ Chemistry Department, LIEC, Federal University of São Carlos, UFSCar, P. O. Box 676, 13565-905, São Carlos, SP, Brazil

$\dagger$ Electronic supplementary information (ESI) available. See DOI: $10.1039 / \mathrm{c} 7 \mathrm{ra} 12727 \mathrm{~h}$ 
From a different point of view, sol-gel routes, such as, the Pechini method, ${ }^{15}$ have not been used to prepare this oxide phase. Then, considering the importance of orthorhombic $\mathrm{SnO}_{2}$ and the lack of papers using sol-routes to synthesize it, the aim of this work is the synthesis and structural characterization orthorhombic phase of $\mathrm{SnO}_{2}$ in the nanoparticle system $\left(\mathrm{Sn}_{1-x} \mathrm{Ce}_{x}\right) \mathrm{O}_{2}$, with $x=0,0.05,0.1,0.3,0.7$ and 1.0 using the Pechini method.

\section{Experiment details}

Nanoparticles of $\left(\mathrm{Sn}_{1-x} \mathrm{Ce}_{x}\right) \mathrm{O}_{2}$ were produced using the Pechini method $^{15}$ with different Ce molar concentrations $(x=0,0.05$, $0.1,0.3,0.7,1)$ and synthesis temperatures. Initially, in an $0.5 \mathrm{~L}$ of an aqueous solution of $0.25 \mathrm{~mol} \mathrm{~L}^{-1}$ citric acid (P A Synth), $28.20 \mathrm{~g}$ of tin chloride dihydrate (Sigma-Aldrich) was added. The final solution $\mathrm{pH}$ was controlled using $1 \mathrm{M} / \mathrm{L}$ ammonia solution (Synth) added drop wise until its value is 3 . Then, a white powder of tin citrate was obtained. ${ }^{\mathbf{1 6}}$ The precipitate was washed with $0.7 \mathrm{~L}$ of distilled water and dried in the oven at $70{ }^{\circ} \mathrm{C}$ for $24 \mathrm{~h}$, resulting in the tin citrate monohydrate $\left(\mathrm{C}_{6} \mathrm{H}_{4} \mathrm{O}_{7} \mathrm{Sn}_{2} \cdot \mathrm{H}_{2} \mathrm{O}\right){ }^{16}$ Next, the precursor solution were prepared by dissolving $2 \times$ $10^{-3} \mathrm{~mol}$ tin citrate monohydrate $\left(\mathrm{C}_{6} \mathrm{H}_{4} \mathrm{O}_{7} \mathrm{Sn}_{2} \cdot \mathrm{H}_{2} \mathrm{O}\right)$ in $4.46 \mathrm{~mL}$ ethylene glycol, EG, (Sigma-Aldrich) under stirring at $70{ }^{\circ} \mathrm{C}$, leading to a solution of $0.45 \mathrm{~mol} \mathrm{~L}^{-1}$. It was necessary to add $80 \mu \mathrm{L}$ of concentrated nitric acid to completely dissolve the salt. Separately, $2 \times 10^{-3} \mathrm{~mol}$ ammonium cerium(Iv) nitrate $\left(\mathrm{NH}_{4}\right)_{2} \mathrm{Ce}\left(\mathrm{NO}_{3}\right)_{6}$ (Vetec) was dissolved in $4.46 \mathrm{~mL}$ of EG, under stirring at $70{ }^{\circ} \mathrm{C}$. Afterward, separately, $2 \times 10^{-2} \mathrm{~mol}$ citric acid (CA - P A Synth) was added to these solution, keeping it at constant temperature and stirring. All samples were prepared with the molar ratio of $1: 10: 40$ of total metal salt : citric acid : ethylene glycol, respectively. Then, the proper molar amount of cerium salt solution was added to the Sn salt solution in the following oxide molar composition: $0,0.05,0.10,0.30$, $0.70,1.00$. Then, the solutions were polymerized at $110{ }^{\circ} \mathrm{C}$ for $1 \mathrm{~h}$ and immediately thermal treated using two steps: (i) at $300{ }^{\circ} \mathrm{C}$ for 2 hours using a heating rate of $10{ }^{\circ} \mathrm{C} \mathrm{min}^{-1}$, to inhibit aggregate formation and, (ii) different final temperatures (500, 580,650 or $750{ }^{\circ} \mathrm{C}$ ) for 2 hours to obtain the doped oxides. The second thermal treatment used also $10{ }^{\circ} \mathrm{C} \mathrm{min}^{-1}$ as heating rate. The color of the pure $\mathrm{SnO}_{2}$ is white powder, and, for those samples doped with cerium, their color become yellow.

The crystalline structures of the samples were investigated by X-ray diffraction (XRD) using a Rigaku powder diffractometer (Model D/Max-2500PC) with $\mathrm{CuK}_{\alpha}$ radiation with Bragg-Brentano geometry mode $\theta-2 \theta$ in the range $20-100^{\circ}$ at a scan speed of $0.5^{\circ} \mathrm{min}^{-1}$, with a step of $0.02^{\circ}$. Rietveld refinements ${ }^{17}$ were performed using the free GSAS-EXPGUI software. ${ }^{18,19}$ The quality of the fitting procedure can be followed using the goodness of fit ( $S$ parameter). It is described in the literature if $S$ is close to 1 indicate an excellent fitting process. ${ }^{20}$

The morphology and size of the nanoparticles were examined by Field Emission Scanning Electron Microscopy (FE-SEM) using Supra 35-VP Carl Zeiss, operated at $15 \mathrm{kV}$ and by highresolution Transmission Electron Microscopy (HRTEM) technique, using an FEI microscope (model Tecnai G2 F20, FEI),
$300 \mathrm{kV}$. The chemical analyses of the samples were performed by EDS using a Thermo-Noran EDS.

\section{Results and discussion}

Fig. 1 shows X-ray diffraction patterns measured at room temperature for $\mathrm{SnO}_{2}$ samples, synthesized at 500 (a), 580 (b), 650 (c) and $750{ }^{\circ} \mathrm{C}(\mathrm{d})$. The orange and violet vertical bars correspond to the indexation to the Inorganic Crystal Structure Database, (ICSD no. 39173 and 157450) for the tetragonal and orthorhombic phase $\mathrm{SnO}_{2}$, respectively.

The XRD patterns shown in Fig. 1a to c are consistent with the tetragonal $\mathrm{SnO}_{2}$ phase (space group: $P 4_{2} / \mathrm{mnm}$ ) with lattice parameters, $a=b=4.7358 \AA$ and $c=3.1851 \AA .{ }^{21}$ Within the limit of resolution in XRD the detection of additional reflections were observed, which excludes the presence of a crystalline secondary phase. In Fig. 1d, samples prepared at $750{ }^{\circ} \mathrm{C}$, in addition to the clear presence of $\mathrm{SnO}_{2}$ tetragonal (marked circles), a second phase, $\mathrm{O}-\mathrm{SnO}_{2}$ peaks was identified. In fact, Bragg peaks (11l) and (02l) (see squares labels in Fig. 1d) correspond to the orthorhombic $\mathrm{SnO}_{2}$ (space group: $\mathrm{Pbcn}$ ) with lattice parameters, $a=4.707 \AA, b=5.710 \AA$ and $c=5.246 \AA^{22}$ Moreover, the weak diffraction peak at $2 \theta=30.6^{\circ}$ and $44.9^{\circ}$, labeled by an asterisk in Fig. 1d, can be indexed as the plane (200) and (211) of the metallic tin phase (Sn), in agreement with that reported in the literature ${ }^{23}$ (ICSD no. 40038).

The XRD patterns were analyzed using Rietveld refinement. ${ }^{17}$ A pseudo-Voigt function of Thompson-Cox-Hasting modified by Young and Desai (pV-TCHZ) as the profile function ${ }^{24}$ used in the fitting process. The full width at half maximum (FWHM) obtained from this procedure was used to estimate the crystallite size $\left\langle D_{\mathrm{X} \text {-ray }}\right\rangle$ and is presented in Table 1 . In addition, lattice

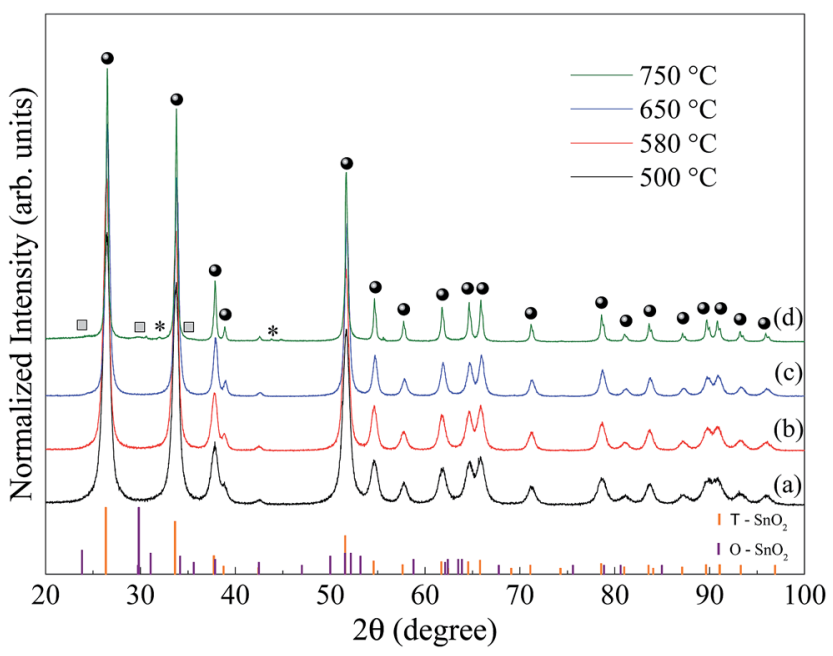

Fig. 1 X-ray diffraction patterns for the $\mathrm{SnO}_{2}$ calcined, (a) 500, (b) 580, (c) 650 and (d) $750{ }^{\circ} \mathrm{C}$ for 2 hours. The circles and squares denote the tetragonal and orthorhombic $\mathrm{SnO}_{2}$ peaks, respectively; the asterisk denotes the peaks of metallic $\mathrm{Sn}$; the orange and violet bars, respectively, correspond to the indexation of the diffraction peaks for $\mathrm{SnO}_{2}$ tetragonal (ICSD 39173) and orthorhombic (ICSD 157450). 
Table 1 Lattice parameters, unit cell volume, crystallite size, lattice strain and goodness of the fit procedure, obtained from the Rietveld refinement data for $\mathrm{SnO}_{2}$ calcined at 500,580, 650 and $750{ }^{\circ} \mathrm{C}$. With, (T) tetragonal phase, (O) orthorhombic phase and (M) metallic phase

\begin{tabular}{|c|c|c|c|c|c|c|c|}
\hline \multirow[b]{2}{*}{ Temp $\left({ }^{\circ} \mathrm{C}\right) /$ phase } & \multicolumn{3}{|c|}{ Lattice parameter $(\AA)$} & \multirow[b]{2}{*}{ Cell volume $\mathrm{V}\left(\AA^{3}\right)$} & \multirow[b]{2}{*}{$\left\langle D_{\text {X-ray }}\right\rangle(\mathrm{nm})$} & \multirow[b]{2}{*}{ Strain (\%) } & \multirow[b]{2}{*}{$S$} \\
\hline & $a(\AA)$ & $b(\AA)$ & $c(\AA)$ & & & & \\
\hline $580 / \mathrm{T}$ & 4.735 & 4.735 & 3.185 & 71.41 & 29.8 & 0.5127 & 1.48 \\
\hline $650 / \mathrm{T}$ & 4.742 & 4.742 & 3.188 & 71.67 & 29.9 & 0.6261 & 1.52 \\
\hline $750 / \mathrm{T}$ & 4.740 & 4.740 & 3.188 & 71.62 & 50.3 & 0.1260 & \\
\hline
\end{tabular}

parameters, unit cell volume, lattice strain and goodness of fit, $(S)$, obtained by the Rietveld refinement are also listed in Table 1.

The goodness of fit indicator $S$ shows the good quality of structural refinement data. A change was observed in the lattice parameters and consequently in the volume of the unit cell as a function of the increase in the synthesis temperature.

As shown in Fig. 1 there is a narrowing in the FWHM of the Bragg peak with increasing synthesis temperature. Part of this narrowing is due to the increase in the crystallite size, as calculated by Rietveld refinement (Table 1), which is in good agreement with the literature. ${ }^{25}$ For the sample calcined at $750{ }^{\circ} \mathrm{C}$, Table 1 shows that the size of the crystallite of the majority phase, tetragonal $\mathrm{SnO}_{2}$, is much larger compared to the size of the crystallite of the orthorhombic $\mathrm{SnO}_{2}$. In contrast, we obtained the highest strain value for the orthorhombic $\mathrm{SnO}_{2}$ and a lower value for tetragonal $\mathrm{SnO}_{2}$.

Fig. 2a shows SEM image for the $\mathrm{SnO}_{2}$ sample calcined at $750{ }^{\circ} \mathrm{C}$. In the inset the particle size histogram was obtained from several SEM images fitted by a log-normal distribution. It clearly observed that pure $\mathrm{SnO}_{2}$ particles are larger $(48.0 \pm 0.2)$ and have non-uniform sizes compared to the pure sample calcined at $650{ }^{\circ} \mathrm{C}(29.4 \pm 0.3)$. These data are shown in Fig. SI.1 (ESI $\dagger$ ). High-resolution TEM images (Fig. $2 \mathrm{~b}$ and c) also show that this sample is highly crystalline, which is clearly observed from the Fourier transform (Fig. 2d) of the image. It is possible to observe two sets of planes with lattice spacing of $3.64 \AA$ and $2.98 \AA$, respectively, corresponding to planes (110) and (111) of the orthorhombic of $\mathrm{SnO}_{2}$ phase. It was also possible to observe a plane at $3.34 \AA$, which corresponds to the plane (110) of the tetragonal $\mathrm{SnO}_{2}$ phase (Fig. 2c). The TEM results confirm that both phases of tetragonal $\mathrm{SnO}_{2}$ and orthorhombic coexist in the sample even in the case of non-doped material, $x=0$, synthesized at $750{ }^{\circ} \mathrm{C}$, which is consistent with XRD data (see Fig. 1).

Recent studies developed by Zhang et al. ${ }^{12}$ reported the formation of the orthorhombic phase in $\mathrm{SnO}_{2}$ at atmospheric pressure, for samples doped with $5 \mathrm{~mol} \%$ of $\mathrm{Mn}$, synthesized by co-precipitation. The authors proposed the formation of this phase with distortion of the lattice generated by the doping process of tetragonal $\mathrm{SnO}_{2} \cdot{ }^{12}$ Based on this paper, we decided to study the solubility limit of cerium in $\mathrm{SnO}_{2}$. It is known that the $\mathrm{Ce}^{4+}$ ion has an ionic radius equal to $0.87 \AA$ with coordination number equal to 6 and $\mathrm{Sn}^{4+}$ is smaller (ionic radius $=0.69 \AA$ ), with the same coordination number. ${ }^{14}$ Therefore, the doping of $\mathrm{SnO}_{2}$ using Ce could induce distortions in the lattice, increasing the concentration of the orthorhombic $\mathrm{SnO}_{2}$ phase.

Fig. 3a shows TEM images for the sample $x=0.3$ calcined at $750{ }^{\circ} \mathrm{C}$. A spherical morphology and a reduction in particle size are observed, compared to the undoped sample (Fig. 2a). Fig. 3b shows the HRTEM image which confirms both $\mathrm{SnO}_{2}$ phases, with the $d$-spacing at $3.34 \AA$ and $2.98 \AA$ corresponding to the tetragonal (110) and orthorhombic (111) planes, respectively. We also observed the $d$-spacing at $3.12 \AA$, which corresponds to the plane (111), confirming the segregation of the $\mathrm{CeO}_{2}$ cubic phase. The energy-dispersion X-ray spectroscopy (EDS)
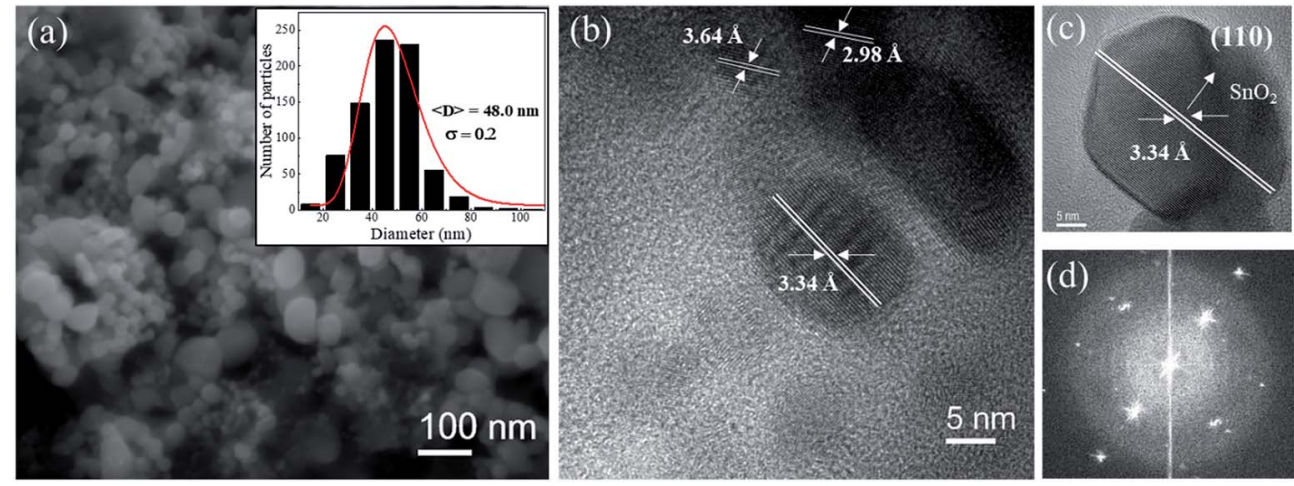

Fig. 2 (a). FE-SEM image of the sample $\mathrm{SnO}_{2}$ calcined at $750^{\circ} \mathrm{C}$. (b) HRTEM image of a set of nanoparticles. (c) HRTEM image of an individual $\mathrm{SnO}_{2}$ nanoparticle indicating the interplanar distances characteristic of tetragonal tin dioxide and the corresponding Fourier transform in (d). The insert: particle size histogram fitted with a log-normal size distribution. 

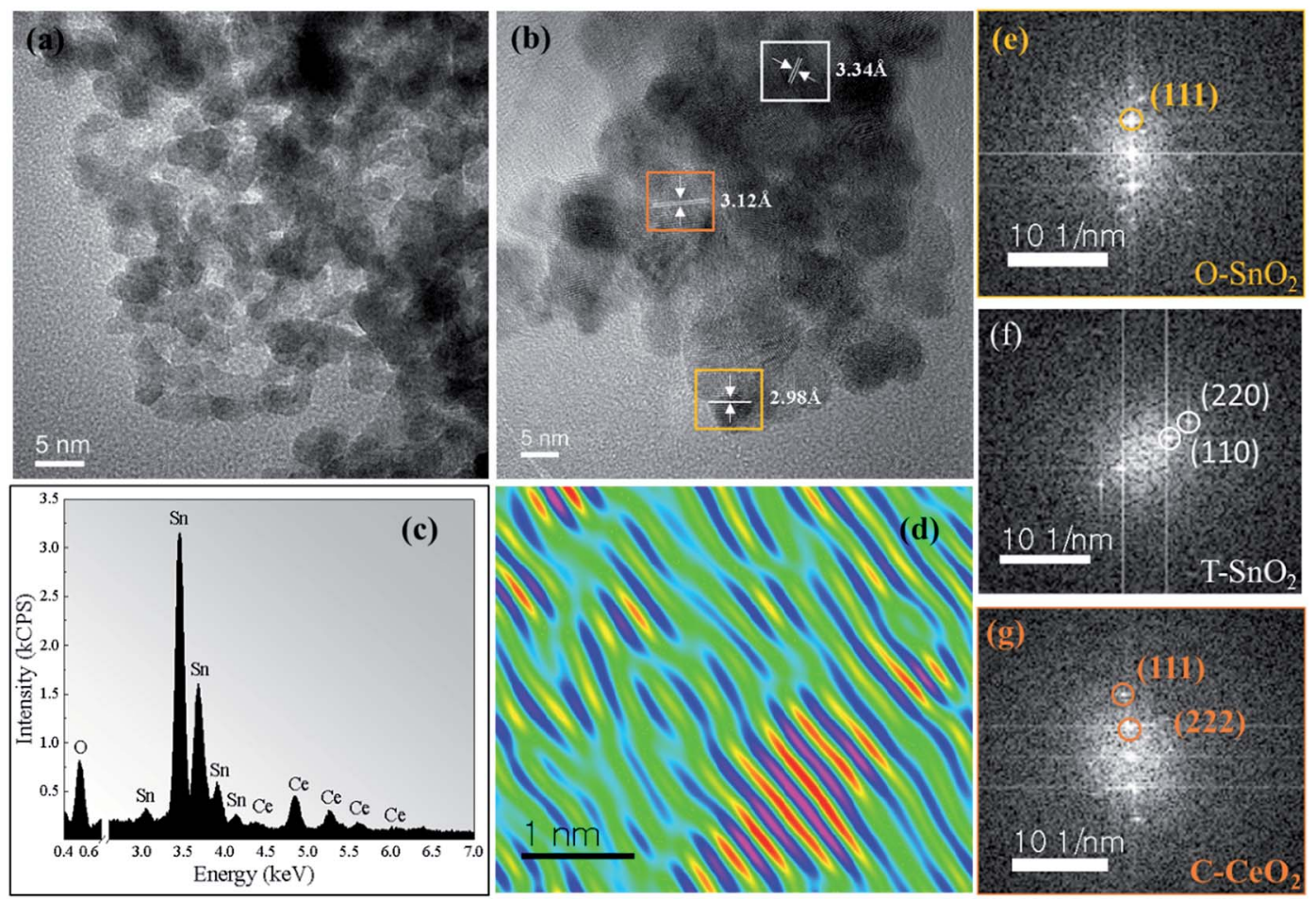

Fig. 3 (a) TEM image of the sample $x=0.3$ calcined at $750{ }^{\circ} \mathrm{C}$. (b) HRTEM image (c) EDS spectrum of the sample. (d) Reconstructed HRTEM image of a $\mathrm{CeO}_{2}$ particle, which shows the lattice mismatch between $\mathrm{CeO}_{2}$ plans. (e-g) FFT pattern referring to the orthorhombic (O-SnO$)_{2}$, tetragonal $\left(\mathrm{T}-\mathrm{SnO}_{2}\right)$ phase and the cubic $\left(\mathrm{C}-\mathrm{CeO}_{2}\right)$ phase.

characterization (Fig. 3c) confirms that the synthesized sample is composed only of $\mathrm{Sn}, \mathrm{Ce}$, and $\mathrm{O}$ and the quantitative analysis of both $\mathrm{Sn}$ and Ce molar ratios of the experimentally and nominally obtained composition is in good agreement, which is presented in Table SI.2 (ESI $\dagger$ ). Fig. 3d shows the reconstructed HRTEM image of one region corresponding to $\mathrm{CeO}_{2}$ particle. It is clearly observed that the sample has structural defects, observed in the Figure by the lack of linear behavior of the crystalline planes. It is possible this occurs due to the distortions in the atomic planes of the $\mathrm{CeO}_{2}$ phase. In the Fig. 3e-g, respectively, the FFT pattern obtained from each region of Fig. $3 \mathrm{~b}$ is shown, i.e., orthorhombic and tetragonal $\mathrm{SnO}_{2}$ phase and the cubic $\mathrm{CeO}_{2}$ phase.

The XRD patterns for the samples $\left(\mathrm{Sn}_{1-x} \mathrm{Ce}_{x}\right) \mathrm{O}_{2}$ changing the molar concentration of $\mathrm{Ce}(x=0,0.05,0.1,0.3,0.7,1)$ calcined at $750{ }^{\circ} \mathrm{C}$ for 2 hours are shown in Fig. 4 . We also show the difference (blue line) between the experimental and calculated patterns, which were evaluated by the Rietveld method. All patterns shown in Fig. 4 indicate that both structures, tetragonal and orthorhombic of $\mathrm{SnO}_{2}$ coexist within the samples in the range from 0 to $x=0.3$. No diffraction peak associated to the formation of cerium oxide $\left(\mathrm{CeO}_{2}\right)$ was detected up to the concentration $x=0.1$. However, by increasing the concentration to higher values, $x=0.3,0.7$ and 1 , the Bragg peaks of $\mathrm{CeO}_{2}$ fluorite structure can be observed space group: $F m \overline{3} m$ and lattice parameter, $a=b=c=5.4124 \AA$ (ICSD no. 72155).

The structural parameters calculated by the Rietveld refinement are listed in Table 2, which show a molar percentage for each phase, lattice parameters, unit cell volume, crystallite size, lattice strain and goodness of fit values, which is an indicator that the refinement quality is suitable. Table 2 shows that while the unit cell volume of the tetragonal $\mathrm{SnO}_{2}$ did not present significant changes as the Ce concentration increases $10 \mathrm{~mol} \%$, the orthorhombic of $\mathrm{SnO}_{2}$ phase exhibits an expansion in the structure, i.e., there is an increase in the volume of the unit cell,

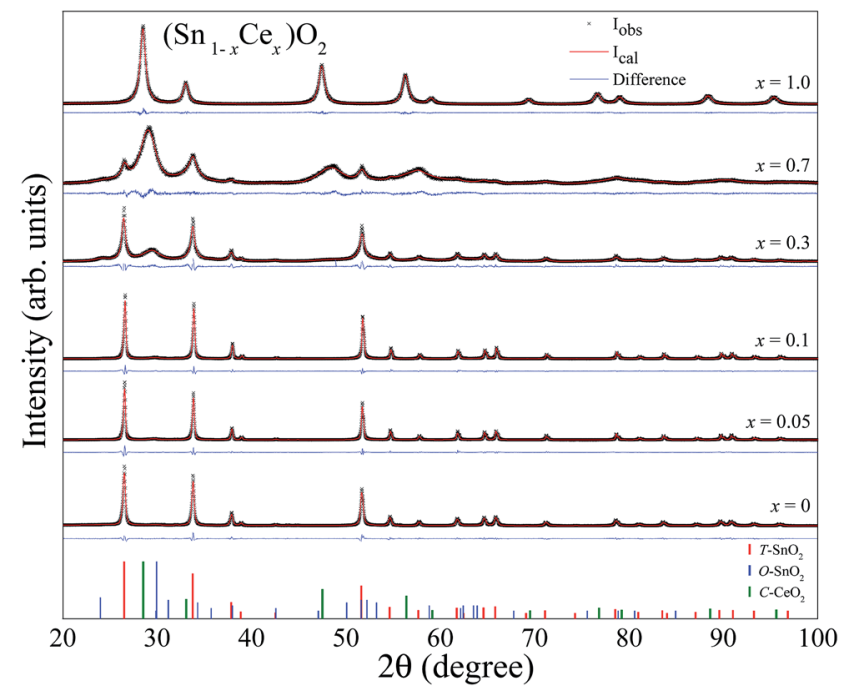

Fig. 4 X-ray diffraction patterns for the $\left(\mathrm{Sn}_{1-x} \mathrm{Ce}_{x}\right) \mathrm{O}_{2}(x=0,0.05,0.1$, $0.3,0.7,1)$ nanoparticles synthesized at $750{ }^{\circ} \mathrm{C}$. The solid lines are the fittings using the Rietveld method (red lines) and difference between the experimental and calculated patterns (blue lines). 
Table 2 List of parameters obtained from the Rietveld refinement of the XRD patterns for the $\left(\mathrm{Sn}_{1-x} \mathrm{Ce}_{x}\right) \mathrm{O}_{2}(x=0,0.05,0.1,0.3,0.7,1)$ nanoparticles synthesized at $750^{\circ} \mathrm{C}$. Phase, molar percentage for each phase, lattice parameters, unit cell volume, crystallite size, lattice strain and goodness of the fit procedure

\begin{tabular}{|c|c|c|c|c|c|c|c|c|c|}
\hline$\left(\mathrm{Sn}_{1-x} \mathrm{Ce}_{x}\right) \mathrm{O}_{2}$ & Phases & (\% molar) & \multicolumn{3}{|c|}{ Lattice parameter $(\AA ̊)$} & $\begin{array}{l}\text { Cell volume V } \\
\left(\AA^{3}\right)\end{array}$ & $\begin{array}{l}\left\langle D_{\mathrm{X}-\text { ray }}\right\rangle \\
(\mathrm{nm})\end{array}$ & Strain (\%) & $S$ \\
\hline & $\mathrm{O}-\mathrm{SnO}_{2}$ & 11.27 & 4.727 & 5.650 & 5.271 & 140.10 & 4.8 & 3.6819 & \\
\hline & M-Sn & 1.15 & 5.828 & 5.828 & 3.178 & 107.90 & 40.4 & 1.0480 & \\
\hline$x=0.05$ & $\mathrm{~T}-\mathrm{SnO}_{2}$ & 88.97 & 4.740 & 4.740 & 3.188 & 71.62 & 74.3 & 0.1087 & 1.90 \\
\hline \multirow[t]{3}{*}{$x=0.1$} & $\mathrm{~T}-\mathrm{SnO}_{2}$ & 89.65 & 4.740 & 4.740 & 3.188 & 71.62 & 74.9 & 0.1087 & \multirow[t]{3}{*}{1.78} \\
\hline & $\mathrm{O}-\mathrm{SnO}_{2}$ & 9.44 & 4.701 & 5.719 & 5.305 & 142.60 & 12.2 & 4.0458 & \\
\hline & $\mathrm{M}-\mathrm{Sn}$ & 0.91 & 5.828 & 5.828 & 3.171 & 107.70 & 27.6 & 1.0337 & \\
\hline \multirow[t]{3}{*}{$x=0.3$} & $\mathrm{~T}-\mathrm{SnO}_{2}$ & 50.87 & 4.743 & 4.743 & 3.187 & 71.70 & 25.0 & 0.1125 & \multirow[t]{3}{*}{1.76} \\
\hline & $\mathrm{O}-\mathrm{SnO}_{2}$ & 40.90 & 4.798 & 5.658 & 5.282 & 143.40 & 6.5 & 3.3376 & \\
\hline & $\mathrm{CeO}_{2}$ & 8.23 & 5.323 & 5.323 & 5.323 & 150.70 & 3.6 & 1.1425 & \\
\hline
\end{tabular}

suggesting the formation of a substitutional solid solution. Since, $\mathrm{Ce}^{4+}$ ions have a larger ionic radius than $\mathrm{Sn}^{4+}$, with the same coordination number, its incorporation into the orthorhombic $\mathrm{SnO}_{2}$ structure justify the increase of the volume of the unit cell. However, the solubility of Ce ions in $\mathrm{SnO}_{2}$ without phase segregation is limited to $10 \mathrm{~mol} \%$. Above this concentration, the segregation of cerium oxide phase can be observed. Table 2 shows that the crystallite size of $\mathrm{T}-\mathrm{SnO}_{2}$ is much larger than that of $\mathrm{O}-\mathrm{SnO}_{2}$ and presents lower strain values. This probably occurs due to the decrease in internal stresses when crystallite size increases. Another important characteristic due to the incorporation of cerium in $\mathrm{SnO}_{2}$ is the disorder in the crystalline structure created by the stacking faults in the crystal due to the difference of ionic radius, resulting in increased strain.

Fig. 5 shows the summarization of these results plotting the molar concentration obtained by the Rietveld refinement for

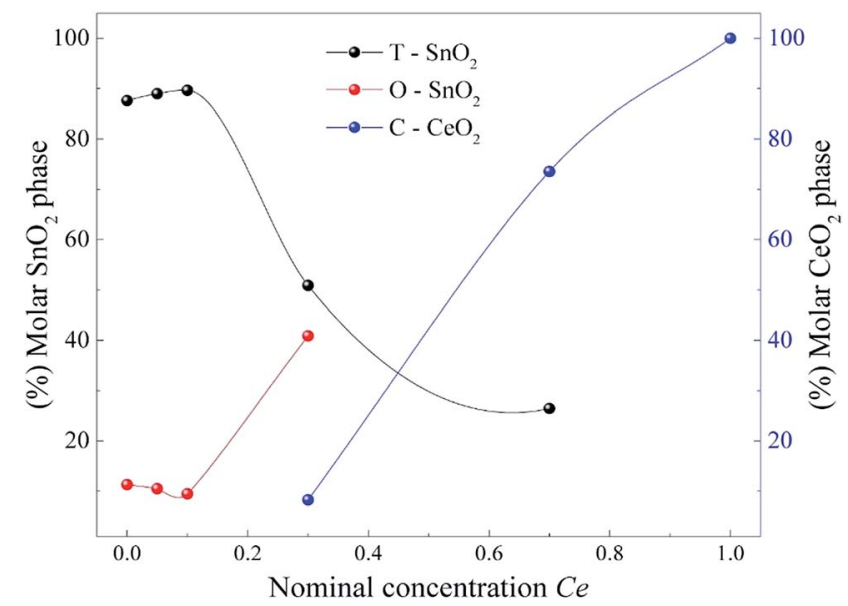

Fig. 5 Molar concentration obtained by the Rietveld refinement for each oxide as a function of the nominal Ce concentration. each oxide as a function of the nominal Ce concentration. The results show that the introduction of different Ce concentrations produces different conditions to stabilize the orthorhombic phase of $\mathrm{SnO}_{2}$. This Figure corroborates the data presented in Fig. 4, in which the amount of $\mathrm{O}^{-\mathrm{SnO}_{2}}$ phase increases as the Ce nominal concentration increases to $30 \mathrm{~mol} \%$. The maximum amount of $\mathrm{O}-\mathrm{SnO}_{2}$ obtained is $41 \%$ for the sample synthesized at $750{ }^{\circ} \mathrm{C}$ with $30 \mathrm{~mol} \%$ of Ce dopant.

It is well established in the literature that the orthorhombic $\mathrm{SnO}_{2}$ phase was originally observed only in experiments with high pressures and temperatures. ${ }^{8,9}$ However, recently Zhang et al. using the chemical co-precipitation method, reported the formation of the orthorhombic phase of $\mathrm{SnO}_{2}$ at atmospheric pressure, when the samples were doped with $5 \mathrm{~mol} \%$ of $\mathrm{Mn} .{ }^{12}$ Our results show that the orthorhombic phase already appears in the pure sample, although with a small molar fraction, reaching a molar fraction of approximately $41 \%$ when we increase the concentration of Ce to $x=0.3$ (see Fig. 5).

The Pechini method proved to be an effective alternative for the synthesis of orthorhombic $\mathrm{SnO}_{2}$, possibly due to the number of defects generated in the thermal treatment process. However, the process of incorporating $\mathrm{Ce}$ in the $\mathrm{SnO}_{2}$ phase led to an increase in the concentration of the orthorhombic phase, possibly due to the ionic radius difference of $\mathrm{Ce}^{4+}(0.87 \AA)$ and $\mathrm{Sn}^{4+}(0.69 \AA)$ leading to the disorder of the crystal structure created by stacking faults in the crystal.

\section{Conclusions}

In this work, we have successfully obtained nanoparticles of $\left(\mathrm{Sn}_{1-x} \mathrm{Ce}_{x}\right) \mathrm{O}_{2}$ using the Pechini method. The reflections on the XRD pattern and clear lattice fringes observed in the HRTEM images confirm the formation of the orthorhombic of $\mathrm{SnO}_{2}$ phase with $x=0,0.05,0.1$ and 0.3 , synthesized at $750{ }^{\circ} \mathrm{C}$. Through the Rietveld refinement analyzes it can be observed 
that the sample with 0.3 moles of cerium reaches a significant molar fraction of the orthorhombic phase, approximately $41 \%$. The reducing atmosphere generated by the heat treatment of the samples and the strain originated due to the difference of ionic rays between the tin and cerium ion can play a crucial role in the formation of orthorhombic phase $\mathrm{SnO}_{2}$. The synthesis method used proved to be a promising alternative route for the preparation of orthorhombic $\mathrm{SnO}_{2}$.

\section{Conflicts of interest}

There are no conflicts to declare.

\section{Acknowledgements}

This work was supported by the FAPESP (2013/07296-2 and 2017/24995-2), CAPES and CNPq Brazilian agencies.

\section{References}

1 L. Renard, O. Babot, H. Saadaoui, H. Fuess, J. Brötz, A. Gurlo, E. Arveux, A. Klein and T. Toupance, Nanoscale, 2012, 4, 6806-6813.

2 J. Arbiol, E. Comini, G. Faglia, G. Sberveglieri and J. R. Morante, J. Cryst. Growth, 2008, 310, 253-260.

3 C. C. Sno, S. Cells, A. Hossain, J. R. Jennings, Z. Y. Koh and Q. Wang, ACS Nano, 2011, 5, 3172-3181.

4 A. Dodd, A. McKinley, M. Saunders and T. Tsuzuki, Nanotechnology, 2006, 17, 692-698.

5 H.-S. Woo, I.-S. Hwang, C. W. Na, S.-J. Kim, J.-K. Choi, J.-S. Lee, J. Choi, G.-T. Kim and J.-H. Lee, Mater. Lett., 2012, 68, 60-63.

6 J. Haines and J. M. Le, Phys. Rev. B: Condens. Matter Mater. Phys., 1997, 55, 144-154.

7 L. G. Liu, Science, 1978, 199, 422-425.
8 Z. Chen, J. K. L. Lai and C.-H. Shek, Appl. Phys. Lett., 2006, 89, 231902.

9 F. J. Lamelas and S. A. Reid, Phys. Rev. B: Condens. Matter Mater. Phys., 1999, 60, 9347-9352.

10 A. Prodan, N. Vene, F. Sevgek and M. Hudomalj, Thin Solid Films, 1987, 147, 313-319.

11 L. Kong, J. Ma, Z. Zhu, C. Luan, X. Yu and Q. Yu, Mater. Lett., 2010, 64, 1350-1353.

12 Q. Zhang, P. Liu, C. Miao, Z. Chen, C. M. Lawrence Wu and C.-H. Shek, RSC Adv., 2015, 5, 39285-39290.

13 F. J. Lamelas, J. Appl. Phys., 2004, 96, 6195.

14 R. D. Shannon, Acta Crystallogr., Sect. A: Cryst. Phys., Diffr., Theor. Gen. Crystallogr., 1976, 32, 751-767.

15 M. P. Pechini, Method of preparing lead and alkaline earth titanates and niobates and coating method using the same to form a capacitor, US3330697 A, Patent, 1967.

16 M. M. Besso, Tin salts of citric acid and method of preparation, US3213120, Patent, 1965.

17 R. A. Young, The Rietveld Method. I.U.C, Oxford University Press Inc., New York, 1995.

18 A. C. Larson and R. B. Von Dreele, Los Alamos Natl. Lab. Rep., 2004, pp. 86-748.

19 B. H. Toby, J. Appl. Crystallogr., 2001, 34, 210-213.

20 L. B. McCusker, R. B. Von Dreele, D. E. Cox, D. Louër and P. Scardi, J. Appl. Crystallogr., 1999, 32, 36-50.

21 H. Seki, N. Ishizawa, N. Mizutani and M. Kato, Powder Diffr., 1989, 4, p156-p160.

22 L. Gracia, A. Beltrán and J. Andrés, J. Phys. Chem. B, 2007, 111, 6479-6485.

23 J. A. Lee and G. V. Raynor, Proc. Phys. Soc., London, Sect. B, 1954, 67, p737-p747.

24 R. Young and P. Desai, Arch. Nauki Mater., 1989, 10, 71-90.

25 A. Maciel, P. Lisboa-Filho, E. Leite, C. Paiva-Santos, W. Schreiner, Y. Maniette and E. Longo, J. Eur. Ceram. Soc., 2003, 23, 707-713. 